\title{
ON THE INVERSION OF SUGAR BY SALTS. NO. 2.
}

\author{
BY J. H. LONG. \\ Received June 29, 3896.
}

$\mathrm{N}$ a recent paper $^{1} \mathrm{I}$ have shown that in their behavior with cane sugar solutions many so-called neutral salts closely resemble weak mineral acids. Salts of the heavy metals in general have the power of inverting sugar solutions, and in some cases very rapidly, especially at an elevated temperature. The same fact has been pointed out for certain salts by others, notably by Walker and Aston, ${ }^{2}$ who determined the speed of inversion of four nitrates, comparing them with dilute nitric acid. This inversion is due to the hydrolysis of the salts in question, the hydrogen of the acids formed being in all cases, probably, the active catalytic agent.

In my former paper I gave some results obtained in a preliminary investigation on ferrous iodide with very strong sugar solutions, and in the present paper I shall give the results obtained with other salts, as well as more extended tests with the iodide.

ME'THOD.

In the experiments before reported I made very strong syrups containing usually fifty grams of sugar in $100 \mathrm{cc}$., and to these syrups before final dilution weighed amounts of the salts were added, the volume being brought up to Ioo $\mathrm{cc}$. with distilled water. In the following series of tests the amount of sugar present is much smaller, being in all cases fifty grams in $250 \mathrm{cc}$. of the finished solution. This solution is much stronger than is usually employed in inversion experiments, but with many of the salts dissolved weaker sugar solutions could not be well used. The ferrous salts, especially, require relatively large amounts of sugar to hold them in clear solution, and as many of the experiments given below were made on such salts, it was decided to employ the same weight of sugar in all cases. For each experiment, therefore, fifty grams of pure sugar was dissolved in water in a $250 \mathrm{cc}$. flask by aid of heat. The strong syrup was cooled and to it was added the salt in the powdered form or dissolved in a little water. After securing a complete

1 This Journal, 18, 120.

$2 J$. Chem. Soc, July, I895. 
solution in either way, it was diluted to the mark and shaken to mix thoroughly.

The syrup so made was poured into small tubes of thin glass for inversion. These tubes held about twenty $\mathrm{cc}$. and were three-fourths filled. They were cleaned for use by boiling in hydrochloric acid and then in distilled water repeatedly. After having been employed for several series of tests it was found sufficient to soak them twenty-four hours in weak acid, and then in distilled water, rinsing thoroughly finally. After receiving the sugar solutions they were closed with perforated rubber stoppers holding each a short glass tube with capillary opening. The tubes were placed in a receptacle, which was finally immersed in the water of a thermostat holding over twenty liters. The receptacle for the tubes consists essentially of two copper disks, twenty-five $\mathrm{cm}$. in diameter, soldered six $\mathrm{cm}$. apart on a copper rod as an axis. The lower disk is furnished with fine perforations, and the upper one with larger openings to receive the tubes. The copper axis below the lower disk ends in a hardened point, resting in a socket, and is extended above to a length of fifteen $\mathrm{cm}$., ending in a grooved pulley around which a belt passes. Power applied to this belt rotates the tube receptacle, which at the same time keeps the water of the thermostat in motion. The thermostat itself consists of a large copper oven covered with asbestos boards on five sides. The top has perforations for the temperature regulator, thermometer and rotating axis of the tube receptacle. A section of the top can be quickly removed to take out tubes, but at other times should be left closed to exclude light. The capillary tubes in the stoppers closing the inversion tubes project about two cm. above the water.

With the apparatus employed it was possible to maintain a constant high temperature with a little watching through ten hours. A temperature of $85^{\circ}$ was held with variation of less than $0 . I^{\circ}$ in either direction. With many salts the rate of inversion is exceedingly slow at ordinary temperatures, in fact almost imperceptible. For convenience in working, therefore, it was found necessary to invert at a high temperature, and $85^{\circ}$ was 
chosen. In a few instances a slightly higher temperature was employed, but the results obtained are not included below.

The reaction between the sugar and salt is probably in most instances analogous to that between sugar and weak acids, and the rate of inversion may therefore be expressed by the same differential equation:

$$
\frac{d x}{d t}=K(A-x) \text {. }
$$

The integration of this for $t$ and $x=0$, together, leads to the well known formula:

$$
K=\frac{\mathrm{I}}{t} \text { nat. } \log \cdot \frac{A}{A-x},
$$

where $A$ represents the amount of sugar present at the beginning of the inversion, $x$ that inverted at any time, $t$, of an observation, and $K$ the "constant" or " coefficient" of inversion.

As the reaction is most easily followed by means of the polaristrobometer, $A$ is conveniently measured by the total change in rotation which is observed between the beginning of the reaction and after complete inversion. $x$ is measured by the change of rotation from the beginning up to the time, $t$, of any observation. For convenience common logarithms are employed in all the calculations below. As the sugar solutions were mixed with the inverting substances at a low temperature, the intervals, $t$, could be reckoned only from the time when the mixtures in the tubes had reached the constant temperature of the experiment. Preliminary tests were therefore made to determine several points of practical manipulation. The thermostat was first brought to a temperature of about $87^{\circ}-88^{\circ}$, and the filled experimental tubes and their receptacle immersed in it. From this a fall of temperature resulted, because of the low temperature of the solution. In five or six minutes the constant temperature of $85^{\circ}$ was reached, and by regulation of the gas flame this was maintained. In another set of experiments it was found that the solutions in the experimental tubes could be brought to a temperature of $85^{\circ}$ from the room temperature in four to six minutes. It appeared, therefore, that ten minutes was amply sufficient time to allow, after introducing the tubes into the 
thermostat, before beginning the actual observations, and this was done in all cases in the experiments given below. In the case of bodies which invert but slowly there is little objection to the loss of this first ten minutes of the reaction, but in a few instances it was found to be a decided drawback, as will be seen below.

Usually $250 \mathrm{cc}$. of the solution was prepared for experiment, and this was filled into fifteen or sixteen tubes, and put into the thermostat. At the end of ten minutes a tube was withdrawn and cooled very quickly by immersion in cold water, or by holding it under a flowing hydrant. The contents were then poured into a polarization tube and polarized at the constant temperature of $20^{\circ}$ in most cases. In a few tests made in warm weather a temperature of $25^{\circ}$ was maintained in the dark room and in the water flowing around the ubservation tube. This first observation gives the initial rotation, and the time of removing the tube may be put as $t=0$. Tubes were removed at different intervals following and treated in the same manner. The results of the polarizations were always very constant during the first few hours heating in the thermostat, as was found by removing and polarizing the contents of three tubes, but after five or six hours less regular results were found, and I adopted the plan of taking the mean result obtained by examining two or three tubes. With fifteen or sixteen tubes I made observations at eight or nine intervals.

After polarizing the liquids in the last tubes removed, the contents were mixed, returned to a tube and heated longer to obtain the end point of the reaction, that is, the point of complete inversion. The point found in this manner does not always agree with that calculated from the known weight of pure cane sugar in the original solution. Even with dilute acids the phenomenon of inversion is not as simple a thing as usually represented. As shown by Gubbe ${ }^{1}$ and others, the specific rotation of invert sugar depends not only on the concentration, but on the time, temperature and acid used. Prolonged heating with salts produces in many cases, apparently, a slight 
decomposition of the levulose, from which the negative rotation of the invert sugar is found smaller than it should be theoretically. In a few instances, however, the negative rotation of the invert sugar was increased. From the experiments of Gubbe it may be calculated that fifty grams of cane sugar in $250 \mathrm{cc}$. would yield a solution after inversion, which in a $200 \mathrm{~mm}$. tube should show a negative rotation of $-8.6^{\circ}$. The rotation observed in my experiments was usually about $-8.3^{\circ}$, but an accurate determination was not always possible, as some of the solutions became slightly colored before inversion was quite complete, and in other cases a negative rotation once observed seemed to grow slightly less on longer heating, making the exact end point somewhat uncertain. The discrepancies were not large in any case, however, and I decided to take $-8.3^{\circ}$ as the true end point for the $200 \mathrm{~mm}$. tube, and $-4.15^{\circ}$ for the $100 \mathrm{~mm}$. tube.

With some of the salts examined the velocity coefficient, $K$, is practically constant, with others it increases with the time, while in still other cases it decreases.

The sugar used in all the experiments was crystallized cut loaf of high degree of purity, and selected for the purpose. With fifty grams in $100 \mathrm{cc}$. it yields a solution of almost perfect clearness, which can be easily polarized in a $400 \mathrm{~mm}$. tube. Weaker solutions yield, on inversion, results which agree perfectly with the theoretical requirement.

POTASSIUM ALUM.

Solutions of this salt invert very rapidly. A sample of pure alum was crystallized several times from distilled water to secure a product free from traces of uncombined sulphuric acid, sometimes present in the commercial article. This carefully purified salt was used in all the inversion tests. In the tables below, $t$ refers to the time in minutes, and under $\alpha$ is given the observed angle of rotation in degrees and hundredths. 


\section{EXPERIMENT I.}

$\mathrm{K}_{2} \mathrm{Al}_{9}\left(\mathrm{SO}_{4}\right)_{4} .24 \mathrm{H}_{2} \mathrm{O} . \quad \frac{N}{64}$.

In $250 \mathrm{cc}$, fifty grams of sugar $+0.617 \mathrm{gram}$ of alum.

$$
A=33.03^{\circ} \text {. }
$$

\begin{tabular}{rrccc}
\multicolumn{1}{r}{$t}$. & $\alpha$, & $x$. & $\log \cdot \frac{A}{A-x} \cdot$ & $\frac{\mathrm{I}}{t} \log \cdot \frac{A}{A-x}$. \\
0 & $24.73^{\circ}$ & $\ldots \ldots$ & $\ldots \ldots$ & $\ldots$ \\
15 & 20.15 & $4.8^{\circ}$ & 0.06483 & 0.00432 \\
30 & 16.16 & 8.57 & 0.13045 & 0.00434 \\
60 & 9.75 & 14.98 & 0.26243 & 0.00437 \\
90 & 4.85 & 19.88 & 0.39998 & 0.00444 \\
120 & 1.25 & 23.48 & $0.5389 \mathrm{I}$ & 0.00449 \\
150 & $-\mathrm{I} .30$ & 26.03 & $0.6758 \mathrm{I}$ & 0.00449 \\
210 & -4.88 & 29.61 & 0.98488 & 0.00468 \\
270 & -6.40 & $31 . \mathrm{I} 3$ & 1.24016 & 0.00459 \\
& & & & -
\end{tabular}

\section{EXPERIMENT 2.}

$\mathrm{K}_{2} \mathrm{Al}_{2}\left(\mathrm{SO}_{4}\right)_{4} \cdot 24 \mathrm{H}_{2} \mathrm{O} . \quad \frac{N}{32}$.

In $250 \mathrm{cc}$., fifty grams of sugar + I.234 grams of alum.

$$
A=32.37 \text {. }
$$

\begin{tabular}{|c|c|c|c|c|}
\hline$t$. & $\alpha$ & $x$. & log. $\frac{A}{A-x}$. & $=\log \cdot \frac{A}{A-x}$ \\
\hline 0 & $24.07^{\circ}$ & $\ldots$ & $\ldots$ & $\ldots$ \\
\hline I5 & I 7.83 & $6 \cdot 24^{\circ}$ & 0.09300 & 0.00620 \\
\hline 30 & I 2.92 & II.I 5 & 0.18339 & $0.006 \mathrm{I}_{4}$ \\
\hline 60 & $5 \cdot 50$ & 18.57 & 0.37026 & 0.00612 \\
\hline 90 & 0.75 & $23 \cdot 32$ & 0.55349 & 0.00615 \\
\hline 120 & -2.48 & 26.55 & 0.74522 & 0.00621 \\
\hline 150 & $-4 \cdot 7^{6}$ & 28.83 & $0.96 I_{I} 4$ & $0.0064 I$ \\
\hline 210 & -7.00 & 31.07 & 1.39620 & $0.0066 \mathrm{I}$ \\
\hline 270 & -7.80 & $3 \mathrm{~T} .87$ & r. 8 III 7 & $0.0067^{\circ}$ \\
\hline & & & & 0.00632 \\
\hline
\end{tabular}


EXPERIMENT 3 .

$\mathrm{K}_{2} \mathrm{Al}_{2}\left(\mathrm{SO}_{4}\right)_{4} \cdot 24 \mathrm{H}_{2} \mathrm{O}$. $\frac{N}{16}$.

In $250 \mathrm{cc}$, fifty grams of sugar +2.468 grams of alum.

$$
A=3 \text { I.25. }
$$

$\begin{array}{rcccc}t . & \alpha . & x . & \log \cdot \frac{A}{A-x} \cdot & \frac{\mathrm{I}}{t} \log \cdot \frac{A}{A-x} . \\ 0 & 22.95^{\circ} & \ldots . & \ldots . . & \ldots . \\ 15 & \mathrm{~J} 4.80 & 8.15^{\circ} & 0.13 \mathrm{I24} & 0.00875 \\ 30 & 8.79 & 14.16 & 0.262 \mathrm{II} & 0.00873 \\ 60 & 1.07 & 21.88 & 0.523 \mathrm{II} & 0.00872 \\ 90 & -3.03 & 25.98 & 0.77304 & 0.00859 \\ 120 & -5.64 & 28.59 & 1.06997 & 0.00891 \\ 180 & -7.53 & 30.48 & 1.55533 & 0.00864 \\ 240 & -8.15 & 31.10 & 2.31866 & 0.00966 \\ & & & & 0.00886\end{array}$

\section{EXPERIMENT 4.}

$\mathrm{K}_{2} \mathrm{Al}_{2}\left(\mathrm{SO}_{4}\right)_{4} \cdot 24 \mathrm{H}_{2} \mathrm{O} . \quad \frac{N}{8}$.

In $250 \mathrm{cc}$, fifty grams of sugar +.4 .936 grams of alum.

$$
A=30.03 \text {. }
$$

$\begin{array}{rcccc}t . & \alpha . & x . & \log \cdot \frac{A}{A-x} \cdot & \frac{I}{t} \log \cdot \frac{A}{A-x} . \\ 0 & 21.73^{\circ} & \ldots . & \ldots \ldots & \ldots . . \\ 15 & 11.23 & 10.50^{\circ} & 0.18686 & 0.01245 \\ 30 & 4.45 & 17.28 & 0.37205 & 0.01240 \\ 60 & -2.87 & 24.60 & 0.74276 & 0.01238 \\ 90 & -5.95 & 27.68 & 1.10649 & 0.01230 \\ 120 & -7.34 & 29.07 & 1.49529 & 0.01244 \\ 180 & -8.18 & 29.91 & 2.39838 & 0.01332 \\ & & & & 0.01255\end{array}$

$\mathrm{K}_{2} \mathrm{Al}_{2}\left(\mathrm{SO}_{4}\right)_{4} \cdot 24 \mathrm{H}_{2} \mathrm{O} . \quad \frac{N}{4}$.

In $250 \mathrm{cc}$, fifty grams of sugar +9.872 grams of alum.

$$
A=29.19 \text {. }
$$

$\begin{array}{rcccc}t . & \alpha . & x . & \log \cdot \frac{A}{A-x} \cdot & \frac{1}{t} \log \cdot \frac{A}{A-x} . \\ 0 & 20.89^{\circ} & \ldots . . & \ldots . & \ldots \\ 10 & 10.89 & 10.00^{\circ} & 0.18216 & 0.01822 \\ 25 & 2.10 & 18.79 & 0.44820 & 0.01793 \\ 50 & -4.70 & 25.59 & 0.90893 & 0.01818 \\ 90 & -7.73 & 28.62 & 1.70936 & 0.01899 \\ 150 & -8.25 & 29.14 & 2.76626 & 0.01844 \\ & & & & 0.01835\end{array}$


An attempt was made to invert with a half normal solution but at the temperature employed the rate was found to be too rapid for accurate observation.

With the first four solutions no difficulty was found in making accurate polarimetric observations in the $200 \mathrm{~mm}$. tube. The last solution, howcver, became finally somewhat colored, and slightly turbid from precipitation of what appeared to be aluminum hydroxide. A portion, heated i 80 minutes, became too turbid for direct reading and had to be examined in the Ioo $\mathrm{mm}$. tube after filtration. The rotation was found now to be $-3.60^{\circ}$, corresponding to $-7.20^{\circ}$ for the $200 \mathrm{~mm}$. tube, instead of $-8.25^{\circ}$ or $-8.30^{\circ}$. From the slight concentration due to the filtration a still greater negative value instead of a lower one should be expected. We have here an illustration of the fact referred to above, viz., that prolonged heating makes the end point determination somewhat uncertain at times.

It is interesting to note the relation existing between the concentrations of the solutions and their rates of inversion in the above examples. For comparison we can call the lowest concentration unity and arrange them as follows:

$\begin{array}{ccc}\frac{N}{54}^{\text {Conc. }} & \text { I } & k . \\ \frac{V}{32} & 2 & 0.00446 \\ \frac{N}{16} & 4 & 0.00632 \\ \frac{N}{8} & 8 & 0.00886 \\ \frac{N}{4} & 16 & 0.01255 \\ & & 0.01835\end{array}$

Inspection of the table shows that the coefficient, $K$, increases rapidly with the concentration, but is not directly proportional to it. It is apparent that the numbers in the third column vary approximately as the square roots of those in the second, which is clearly shown in the next table.

$\begin{array}{ccc}\text { Conc. } & K . & K_{1} \times \sqrt{\text { Conc. }} \\ \text { I } & 0.00446 & 0.00446 \\ 2 & 0.00632 & 0.0063 \mathrm{I} \\ 4 & 0.00886 & 0.00892 \\ 8 & 0.01255 & 0.0126 \mathrm{I} \\ \mathrm{I} 6 & 0.01835 & 0.01784\end{array}$


The regular results obtained from the aluminum salt are probably due in a measure to the inertness of the hydroxide toward sugar, as well as to the behavior of sulphuric acid in inversion. The bases of the other salts examined below form combinations with sugar more or less readily, not only with saccharose, but also with the products of inversion, so that the normal results of the reaction may be modified in a manner difficult to compute. The rather rapid rate of inversion in the above points to a relatively great degree of hydrolysis in the alum. Walker and Aston ${ }^{1}$ found something similar in a half normal solution of the nitrate, studied at a temperature of $80^{\circ}$. From their polarizations a value of 0.0077 for $K$ was found, and this was much in excess of the values found for other salts at the same time.

\section{FERROUS SULPHATE.}

A sample of the purest obtainable sulphate was recrystallized from water containing a trace of sulphuric acid, then dissolved in distilled water and precipitated by alcohol. The crystal meal secured was washed several times with alcohol and dried by fanning. The finished product was bright green and gave a nearly clear solution with pure water. It still held a trace of alcohol as disclosed by the odor. The experimental solutions were made by dissolving the sugar first and adding to this syrup the weighed sulphate meal. The mixtures were shaken to complete solution without application of heat, and then poured into the tubes for inversion. The solutions soon became. turbid on warming and a minute amount of flocculent precipitate separated, making direct polarization impossible. The readings could be made therefore only after filtration, which was not without slight effect on the result. The total amount of separated hydroxide or basic salt was and remained through the test, minute.

1 Loc. cit. 
$\mathrm{FeSO}_{4} \cdot 7 \mathrm{H}_{2} \mathrm{O} . \stackrel{-N}{\frac{N}{2}}$.

In $250 \mathrm{cc}$, fifty grams of sugar + I $7.3^{8}$ grams of sulphate.

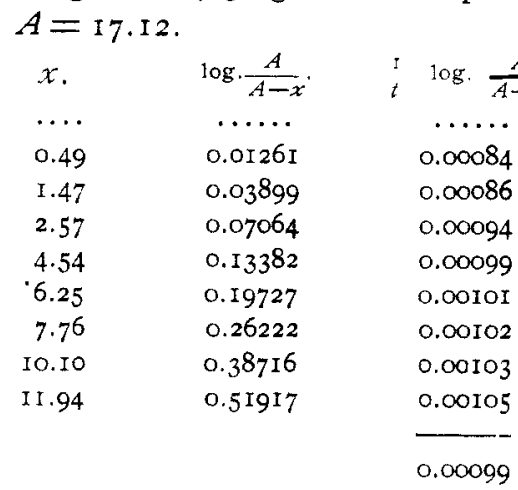

\begin{tabular}{|c|c|c|c|c|}
\hline$t$. & $\alpha$. & $x$. & $\log \cdot \frac{A}{A-x}$ & $\log \frac{A}{A-x}$ \\
\hline o & I 2.97 & $\cdots$ & $\ldots \ldots$ & $\ldots \ldots$ \\
\hline I 5 & 12.48 & 0.49 & $0.0126 I$ & 0.00084 \\
\hline 45 & II. 50 & 1.47 & 0.03899 & 0.00086 \\
\hline 75 & 10.40 & 2.57 & 0.07064 & 0.00094 \\
\hline I 35 & 8.43 & 4.54 & o. $133^{82}$ & 0.00099 \\
\hline I95 & $6.7^{2}$ & 6.25 & 0.19727 & 0.00101 \\
\hline 255 & $5.2 \mathrm{I}$ & $7.7^{6}$ & 0.26222 & 0.00102 \\
\hline 375 & 2.87 & IO.IO & 0.38716 & 0.00103 \\
\hline 495 & 1.03 & II. 94 & 0.51917 & 0.00105 \\
\hline
\end{tabular}

\section{EXPERIMENT 7.}

$\mathrm{FeSO}_{4} \cdot 7 \mathrm{H}_{2} \mathrm{O} . \quad N$.

In $250 \mathrm{cc}$, fifty grams of sugar +34.75 grams of sulphate.

$$
A=\text { I } 7 \text {.10. }
$$

\begin{tabular}{rcccc}
\multicolumn{1}{r}{$t}$. & $\alpha$, & $x$, & $\log \cdot \frac{A}{A-x} \cdot$ & $\frac{1}{t} \log \cdot \frac{A}{A-x}$ \\
0 & $\mathrm{I} 2.95$ & $\ldots$. & $\ldots \ldots$ & $\ldots \ldots$ \\
15 & 12.45 & 0.50 & 0.01289 & 0.00086 \\
45 & $\mathrm{II} .26$ & 1.69 & 0.04520 & 0.00100 \\
75 & 10.08 & 2.87 & 0.07980 & 0.00106 \\
135 & 8.07 & 4.88 & 0.14593 & 0.00108 \\
195 & 6.30 & 6.65 & 0.21388 & 0.00110 \\
255 & 4.70 & 8.25 & 0.28606 & 0.00112 \\
375 & 2.25 & 10.70 & 0.42682 & 0.00114 \\
495 & 0.15 & 12.80 & 0.59953 & 0.00121 \\
& & & & -0.00107
\end{tabular}

Other tests were made with a second preparation of ferrous sulphate from which the alcohol had not been as completely removed. For a half normal solution the coefficient, 0.00094, was found, and for a normal solution the value, 0.00100 , both results being but a trifle lower than those obtained from the pure products. It is possible that the differences may be due to the presence of the trace of alcohol. In any case it is evi- 
dent that with solutions as strong as those used the larger amount of sulphate inverts but little more rapidly than the smaller.

AMMONIUM FERROUS SUPHATE.

But one experiment was made with this salt, a very nice crystallized preparation being used.

\section{EXPERIMENT 8.}

$\left(\mathrm{NH}_{4}\right)_{2} \mathrm{Fe}\left(\mathrm{SO}_{4}\right)_{2} \cdot 6 \mathrm{H}_{2} \mathrm{O} . \quad \frac{N}{2}$.

In $500 \mathrm{cc}$, 100 grams of sugar +49 grams of sulphate.

$$
A=\mathrm{I} 7.08 \text {. }
$$

$\begin{array}{rcccc}t . & \alpha . & x . & \log . \frac{A}{A-x} . & -\frac{\mathrm{I}}{t} \log . \frac{A}{A-x} . \\ 0 & \mathrm{I} 2.93 & \ldots . . & \ldots \ldots . & \ldots \ldots . \\ \mathrm{I} 7 & 12.49 & 0.44 & 0.01 \mathrm{I} 34 & 0.00066 \\ 45 & \mathrm{II} .74 & \mathrm{I} .19 & 0.03137 & 0.00069 \\ 75 & 10.93 & 2.00 & 0.05409 & 0.00072 \\ 105 & 10.13 & 2.80 & 0.07776 & 0.00074 \\ 165 & 8.60 & 4.33 & 0.12698 & 0.00077 \\ 225 & 7.30 & 5.63 & 0.17368 & 0.00077 \\ 345 & 4.60 & 8.33 & 0.29048 & 0.00084 \\ 465 & 2.85 & 10.08 & 0.38739 & 0.00083 \\ 525 & 2.20 & 10.73 & 0.42972 & 0.00082 \\ & & & & \overline{0.00076}\end{array}$

The coefficient is seen to be low, but nearly a constant. In this case, as in that of the ferrous sulphate, the mixture became slightly turbid on heating.

\section{ZINC SULPHATE.}

It is practically difficult to secure a good preparation of zinc sulphate crystallized without the addition of a trace of sulphuric acid. In absence of the acid crystallization is very slow. The preparation used below was made from a chemically pure commercial sample, by crystallizing with a trace of acid first and then from pure water, after heating the solution with pure zinc. The final crystallization to secure fifty grams required weeks for its completion. In my former paper attention was called to the fact that inversion with zinc sulphate is very slow, which is well shown below. The experiment was closed when the sugar was 
about half inverted, and as the coefficient is not regular, it is not possible to estimate accurately the mean rate for the whole period.

\section{EXPERIMENT 9.}

$\mathrm{ZnSO}_{4} \cdot 7 \mathrm{H}_{2} \mathrm{O} . \quad \frac{N}{2} \cdot$

In $250 \mathrm{cc}$, fifty grams of sugar $+\mathrm{I} 7.94$ grams of the sulphate.

$$
A=17.25 \text {. }
$$

$\begin{array}{rcccc}t . & \alpha, & x . & \log \cdot \frac{A}{A-x} \cdot & \frac{\mathrm{I}}{t} \log \cdot \frac{A}{A-x} . \\ 0 & \mathrm{I} 3 \cdot 10^{\circ} & \ldots . & \ldots \ldots . & \ldots \ldots \\ \mathrm{I} 5 & \mathrm{I} 2.88 & 0.22^{\circ} & 0.0055^{\circ} & 0.00037 \\ 45 & \mathrm{I} 2.35 & 0.75 & 0.01935 & 0.00043 \\ \mathrm{I05} & \mathrm{I} 1.34 & \mathrm{I} .75 & 0.04674 & 0.00044 \\ \mathrm{I} 65 & \mathrm{I} 0.40 & 2.70 & 0.07393 & 0.00045 \\ 285 & 8.48 & 4.62 & 0.13539 & 0.00048 \\ 405 & 6.5 \mathrm{I} & 6.59 & 0.20903 & 0.00052 \\ 525 & 4.68 & 8.42 & 0.29083 & 0.00055\end{array}$

MANGANOUS SULPHATE.

After several attempts a salt was obtained crystallized from perfectly neutral solution. Some of the crystals were so irregular in outline that it was not possible to determine from inspection whether they contained four or five molecules of water. Determination of $\mathrm{SO}_{4}$ in the product showed, however, that a very small amount only of the latter salt was present. In making the solutions I assumed for convenience that the compound had the formula $\mathrm{MnSO}_{4} \cdot 4 \mathrm{H}_{3} \mathrm{O}$, and weighed out accordingly,

As I pointed out in my former paper, a solution of manganous sulphate and sugar undergoes a peculiar decomposition when heated, in which a very fine dark substance is thrown out from solution. The amount of this is so small that I could not collect enough for tests, in the work done, but it is still sufficient to make the polarimeter readings very difficult. All solutions had to be filtered before examination, but even with this precaution the readings were often obscure. 
EXPERIMENT IO.

$\mathrm{MnSO}_{4} \cdot 4 \mathrm{H}_{2} \mathrm{O}, \quad \frac{N}{2}$.

In $250 \mathrm{cc}$, fifty grams of sugar + I 3.94 grams of sulphate.

$$
A=34.80 \text {. }
$$

$\begin{array}{rcccc}t . & \alpha . & x . & \log , \frac{A}{A-x} \cdot & \frac{\mathrm{I}}{t} \log \cdot \frac{A}{A-x} . \\ 0 & 26.50^{\circ} & \ldots . & \ldots \ldots . & \ldots \ldots \\ 45 & 26.33 & 0.17^{\circ} & 0.00213 & 0.000047 \\ 75 & 26.15 & 0.35 & 0.00439 & 0.000058 \\ 135 & 25.76 & 0.74 & 0.00934 & 0.000069 \\ 195 & 25.05 & 1.45 & 0.01848 & 0.000095 \\ 315 & 22.33 & 4.17 & 0.05543 & 0.000176 \\ 435 & 19.84 & 6.66 & 0.09226 & 0.000212 \\ 555 & 16.75 & 9.75 & 0.14277 & 0.000257\end{array}$

EXPERIMENT II.

$\mathrm{MnSO}_{4} \cdot 4 \mathrm{H}_{2} \mathrm{O} . \quad N$.

In $250 \mathrm{cc}$, fifty grams of sugar +27.88 grams of sulphate. $A=34.75$.

$\begin{array}{rcccc}t . & \alpha . & x . & \log \cdot \frac{A}{A-x} \cdot & \frac{\mathrm{I}}{t} \log \cdot \frac{A}{A-x} . \\ 0 & 26.45^{\circ} & \ldots \ldots & \ldots \ldots . & \ldots \ldots \\ \mathrm{I} 5 & 26.25 & 0.20^{\circ} & 0.00250 & 0.00017 \\ 45 & 26.00 & 0.45 & 0.00566 & 0.00013 \\ 75 & 25.75 & 0.70 & 0.00883 & 0.00012 \\ \mathrm{I} 35 & 24.90 & 1.55 & 0.0198 \mathrm{I} & 0.00015 \\ \mathrm{I} 95 & 23.00 & 3.45 & 0.0454 \mathrm{I} & 0.00023 \\ 315 & 18.20 & 8.25 & 0.11770 & 0.00037 \\ 435 & 14.45 & 12.00 & 0.18397 & 0.00042 \\ 555 & 9.50 & 16.95 & 0.29053 & 0.00052\end{array}$

EXPERIMENT I 2.

$\mathrm{MnSO}_{4} \cdot 4 \mathrm{H}_{2} \mathrm{O}, 2 \mathrm{~N}$.

In $250 \mathrm{cc}$, fifty grams of sugar +55.76 grams of sulphate. $A=34.42$.

\begin{tabular}{rcccc}
\multicolumn{1}{c}{$t}$. & $\alpha$. & $x$. & $\log \cdot \frac{A}{A-x} \cdot$ & $\frac{\mathrm{I}}{t} \cdot \log \cdot \frac{A}{A-x} \cdot$ \\
0 & $26.12^{\circ}$ & $\ldots$. & $\ldots \ldots$. & $\ldots \ldots$ \\
30 & 25.12 & 1.00 & 0.01280 & 0.00043 \\
90 & 22.80 & 3.32 & 0.04405 & 0.00049 \\
150 & 17.82 & 8.30 & 0.11984 & 0.00080 \\
220 & 12.33 & 13.79 & $0.2223 \mathrm{I}$ & 0.00101 \\
338 & 4.60 & 21.52 & 0.42622 & 0.00126 \\
450 & 0.27 & 25.85 & 0.60383 & 0.00134 \\
570 & -3.80 & 29.92 & 0.88360 & 0.00155
\end{tabular}




\section{EXPERIMENT I 3 .}

$\mathrm{MnSO}_{4} \cdot 4 \mathrm{H}_{2} \mathrm{O} .3 \mathrm{~N}$.

In 250 cc., fifty grams of sugar +83.64 grams of sulphate.

\begin{tabular}{rcccc}
\multicolumn{5}{c}{$A=34.00}$. \\
$t$. & $\alpha$. & $x$. & $\log \frac{A}{A-x} \cdot$ & $\frac{1}{\mathrm{t}} \log \cdot \frac{A}{A-x}$. \\
0 & $25.70^{\circ}$ & $\ldots$. & $\ldots$. & $\ldots$. \\
30 & 24.22 & $1.48^{\circ}$ & 0.01933 & 0.00064 \\
90 & 18.76 & 6.94 & 0.09915 & 0.00110 \\
150 & 11.50 & 14.20 & $0.2348 \mathrm{I}$ & 0.00156 \\
220 & 4.75 & 20.95 & 0.41587 & 0.00189 \\
338 & -2.69 & 28.39 & 0.78252 & $0.0023^{2}$ \\
450 & -6.25 & 31.96 & 1.22185 & 0.00272 \\
570 & -8.05 & 33.75 & 2.13354 & 0.00363
\end{tabular}

The rates of inversion cannot be directly compared in the above experiments because the latter were not carried to completion. In the first case over one-third of the sugar originally present was inverted, in the second case almost exactly one-half, in the third case about six-sevenths, while in the last case the inversion was very nearly complete. By plotting the results it is possible to determine approximately the rate of inversion when just one-half of the sugar has been inverted and this I have: done. The results are given below, and show that the coefficients, $K$, are nearly proportional to the concentrations, these being referred to that of the half-normal solution as unity.

Conc.
1
2
4
6

$\mathrm{K}$.

$$
\begin{gathered}
(0.00032) \\
0.00054 \\
0.00109 \\
0.00172
\end{gathered}
$$

The first coefficient, 0.00032 , is uncertain because it was found by a rather wide extrapolation, but between the others there is fair agreement.

\section{MANGANOUS CHLORIDE.}

The salt used was purified by several crystallizations from the best obtainable Schuchardt product. 
EXPERIMENT I4.

$\mathrm{MnCl}_{2} \cdot 4 \mathrm{H}_{2} \mathrm{O} . \frac{N}{4}$.

In $25^{\circ} \mathrm{cc}$, fifty grams of sugar +6.18 grams of chloride.

\begin{tabular}{rcccc}
\multicolumn{5}{c}{$A=35.00}$. \\
$t$. & $\alpha$. & $x$. & $\log \frac{A}{A-x}$. & $\frac{\mathrm{I}}{t} \log . \frac{A}{A-x}$. \\
0 & $26.70^{\circ}$ & $\ldots$. & $\ldots$. & $\ldots .$. \\
15 & 26.60 & $0.10^{\circ}$ & 0.00124 & 0.00009 \\
45 & 26.30 & 0.40 & 0.00499 & $0.0001 \mathrm{I}$ \\
75 & 26.00 & 0.70 & 0.00878 & 0.00612 \\
135 & 25.25 & 1.45 & 0.01838 & 0.00014 \\
255 & 22.66 & 4.04 & 0.05327 & 0.00021 \\
375 & 18.75 & 7.95 & 0.11190 & 0.00030
\end{tabular}

The high initial rotation here is very extraordinary, corresponding to a specific rotation of $66.75^{\circ}$.

$\mathrm{MnCl}_{2} \cdot 4 \mathrm{H}_{2} \mathrm{O} \cdot \frac{N}{2}$.

EXPERIMENT I5.

In $250 \mathrm{cc}$, fifty grams of sugar +12.35 grams of chloride.

\begin{tabular}{rcccc}
\multicolumn{5}{c}{$A=34.84}$. \\
$t$. & $\alpha$. & $x$. & $\log \frac{A}{A-x}$. & $\frac{1}{t} \log \cdot \frac{A}{A-x}$. \\
0 & $26.54^{\circ}$ & $\ldots$. & $\ldots .$. & $\ldots .$. \\
15 & 26.45 & $0.09^{\circ}$ & 0.00113 & 0.00008 \\
45 & 26.16 & 0.38 & 0.00476 & 0.00011 \\
75 & 25.85 & 0.69 & 0.00869 & 0.00012 \\
135 & 24.52 & 2.02 & 0.02594 & 0.00019 \\
255 & 22.26 & 4.28 & 0.05693 & 0.00022 \\
375 & 17.15 & 9.39 & 0.13639 & 0.00036 \\
495 & 13.00 & 13.54 & 0.21370 & 0.00043 \\
555 & 11.52 & 15.02 & 0.24498 & 0.00044
\end{tabular}

EXXPERIMENT I6.

$\mathrm{MnCl}_{2} \cdot 4 \mathrm{H}_{2} \mathrm{O} . \quad N$.

In $250 \mathrm{cc}$, fifty grams of sugar +24.70 grams of chloride. $A=34.63$.

$\begin{array}{rcccc}t . & \alpha . & x . & \log \frac{A}{A-x} \cdot & \frac{\mathrm{I}}{t} \log \cdot \frac{A}{A-x} . \\ 0 & 26.33^{\circ} & \ldots \ldots & \ldots . . & \ldots . . \\ 15 & 26.12 & 0.2 \mathrm{I}^{\circ} & 0.00264 & 0.00018 \\ 30 & 25.86 & 0.47 & 0.00593 & 0.00020 \\ 60 & 25.15 & 1.18 & 0.01505 & 0.00025 \\ 120 & 23.05 & 3.28 & 0.0432 \mathrm{I} & 0.00036 \\ 180 & 20.07 & 6.26 & 0.08659 & 9.00048 \\ 300 & 15.60 & 10.73 & 0.16105 & 0.00054\end{array}$


$\mathrm{MnCl}_{2} \cdot 4 \mathrm{H}_{2} \mathrm{O} .2 \mathrm{~N}$.

In 250 cc., fifty grams of sugar +49.40 grams of chloride.

$$
A=34.18 \text {. }
$$

$\begin{array}{rcccc}t . & \alpha . & x . & \log \cdot \frac{A}{A-x} \cdot \frac{1}{t} \log \cdot \frac{A}{A-x} \cdot \\ 0 & 25.88^{\circ} & \ldots \ldots & \ldots . & \ldots \\ 15 & 25.38 & 0.50^{\circ} & 0.00640 & 0.00043 \\ 45 & 23.91 & 1.97 & 0.02578 & 0.00057 \\ 75 & 22.21 & 3.67 & 0.04933 & 0.00065 \\ 135 & 18.25 & 7.63 & 0.10971 & 0.00081 \\ 195 & 14.80 & 11.08 & 0.17016 & 0.00087 \\ 345 & 5.25 & 20.63 & 0.40183 & 0.00116\end{array}$

No very plain relation can be found connecting these rates of inversion. The coefficients corresponding to the time of completion of one-third of the inversion are here given.

$\begin{array}{cc}\text { Conc. } & K . \\ \text { I } & (0.00038) \\ 2 & 0.0004 \mathrm{I} \\ 4 & 0.00055 \\ 8 & 0.00088\end{array}$

The first coefficient had to be estimated and is uncertain.

FERROUS CHLORIDE.

Considerable difficulty was experienced in preparing a solution of ferrous chloride devoid of traces of free acid. A weighed excess of pure iron wire was covered with water in a small flask and then the calculated volume of titrated hydrochloric acid was added in amount just sufficient to produce the solution of required strength. The mixture was gently warmed and allowed to stand a short time. Warming was repeated at intervals through several hours, until the liberation of hydrogen became very feeble. The solution so obtained stood five days in the presence of the excess of iron, being boiled twice in the interval, and was then filtered cold into the sugar solution, which was made up to the proper volume with fresh distilled water.

The actual strength of solutions made in this manner was determined by titration later. The two following were almost exactly normal and half-normal.

Both solutions became turbid on heating and had to be fil- 
tered before polarization for the first tests. After the lapse of about two hours the cloudiness disappeared and the solutions then taken from the thermostat were clear enough for direct polarization.

\section{EXPERIMENT I 8.}

$\mathrm{FeCl}_{2}, \quad \frac{N}{2}$.

In $250 \mathrm{cc}$, fifty grams of sugar +7.925 grams of chloride.

\begin{tabular}{rcccc}
\multicolumn{5}{c}{$A=\mathrm{I} 6 . \mathrm{I} 8}$. \\
$t$. & $\alpha$. & $x$. & $\log \frac{A}{A-x} \cdot$ & $\frac{\mathrm{I}}{t} \log \cdot \frac{A}{A-x}$. \\
0 & $\mathrm{I} 2.03^{\circ}$ & $\ldots \ldots$ & $\ldots$. & $\ldots$. \\
$\mathrm{I} 5$ & 9.47 & $2.56^{\circ}$ & 0.07507 & 0.00500 \\
45 & 7.44 & 4.59 & 0.14517 & 0.00322 \\
105 & 5.00 & 7.03 & 0.24783 & 0.00236 \\
$\mathrm{I} 65$ & 3.83 & 8.20 & 0.30725 & 0.00186 \\
285 & 1.90 & 10.13 & 0.42749 & 0.00150 \\
405 & -0.50 & $\mathrm{I} 2.53$ & 0.64696 & 0.00160 \\
525 & -2.01 & 14.04 & 0.87884 & 0.00167
\end{tabular}

EXPERIMENT I 9.

$\mathrm{FeCl}_{2}, N$.

In $25^{\circ} \mathrm{cc}$, fifty grams of sugar $+\mathrm{I} 5.85$ grams of chloride.

\begin{tabular}{rcccc}
\multicolumn{5}{c}{$A=\mathrm{I} 5.7 \mathrm{I}}$. \\
$t$. & $\alpha$. & $x$. & $10 \mathrm{~g} \cdot \frac{A}{A-x}$, & $\frac{\mathrm{I}}{t} \log \cdot \frac{A}{A-x}$. \\
0 & $\mathrm{I} 1.5^{\circ}$ & $\ldots$. & $\ldots$. & $\ldots$ \\
$\mathrm{I} 5$ & 9.40 & $2.16^{\circ}$ & 0.06424 & 0.00428 \\
45 & 6.88 & 4.68 & 0.15360 & $0.0034 \mathrm{I}$ \\
105 & 4.75 & $6.8 \mathrm{I}$ & 0.24679 & 0.00235 \\
$\mathrm{I} 65$ & 3.56 & 8.00 & $0.309 \mathrm{I} 3$ & 0.00188 \\
285 & $\mathrm{I} . \mathrm{I5}$ & $\mathrm{I} 5.4 \mathrm{I}$ & $0.47 \mathrm{I} 90$ & 0.00165 \\
405 & $-\mathrm{I} .42$ & $\mathrm{I} 2.98$ & 0.76002 & 0.00187 \\
525 & -3.25 & $\mathrm{I} 4.8 \mathrm{I}$ & $1.24 \mathrm{I} 94$ & 0.00236
\end{tabular}

These results are very surprising, inasmuch as they show but little difference between the rates for the two concentrations. In both instances the rates rapidly decrease from the beginning and after the sugar has been about half inverted they increase a little. I give next some results from solutions which had not been boiled so thoroughly, and which may have held a little free acid. 


\section{EXPERIMENT 20}

$\mathrm{FeCl}_{2}, 0.52 \mathrm{~N}$.

In $250 \mathrm{cc}$., fifty grams of sugar +8.242 grams of chloride.

$$
A=34.00 \text {. }
$$

\begin{tabular}{rcccc}
\multicolumn{1}{c}{$t}$. & $\alpha$. & $x$. & $\log \cdot \frac{A}{A-x} \cdot$ & $\frac{1}{t} \log \frac{A}{A-x}$ \\
0 & $25.70^{\circ}$ & $\ldots \ldots$ & $\ldots$ & $\ldots$ \\
15 & 20.00 & $5 \cdot 70^{\circ}$ & 0.07969 & $0.0053 \mathrm{I}$ \\
45 & 12.80 & 12.90 & 0.20720 & 0.00460 \\
75 & 9.00 & 16.70 & 0.29343 & $0.0039 \mathrm{I}$ \\
105 & 6.19 & $19.5 \mathrm{I}$ & $0.3704 \mathrm{I}$ & 0.00353 \\
165 & 2.42 & 23.28 & 0.50129 & 0.00304 \\
285 & -1.95 & 27.65 & $0.7277 \mathrm{I}$ & 0.00256 \\
345 & -3.96 & 29.66 & 0.89399 & 0.00258 \\
405 & -5.30 & 31.00 & 1.05436 & 0.00260
\end{tabular}

EXPERIMENT 2 I.

$\mathrm{FeCl}_{2} \cdot 0.98 \mathrm{~N}$.

In $250 \mathrm{cc}$., fifty grams of sugar + I 5.53 grams of chloride.

$$
A=33.60 \text {. }
$$

\begin{tabular}{|c|c|c|c|c|}
\hline$t$. & $\alpha$ & $x$. & $\log \cdot \frac{A}{A-x}$. & $\frac{I}{t} \cdot \log \cdot \frac{A}{A-x}$ \\
\hline 0 & $25.30^{\circ}$ & $\ldots$ & $\ldots$ & $\ldots$ \\
\hline I5 & I9.84 & $5.46^{\circ}$ & 0.07702 & 0.00513 \\
\hline 45 & I 4.20 & II.IO & 0.17416 & 0.00387 \\
\hline 75 & I I. 80 & 13.50 & 0.22314 & 0.00297 \\
\hline 105 & 9.88 & 15.42 & 0.26675 & 0.00254 \\
\hline I65 & 7.65 & 17.65 & 0.32358 & 0.00196 \\
\hline 285 & $I .45$ & 23.85 & 0.53734 & 0.00188 \\
\hline 345 & $-I .50$ & 26.80 & $0.693^{8} 3$ & $0.0020 \mathrm{~K}$ \\
\hline
\end{tabular}

The effect of free acid is not apparent. Six other experiments were made with normal and half-normal ferrous chloride solutions, the results of which were very similar to those above. In all cases the constant was found to increase before the completion of the inversion.

The constant for $0.001 N$ hydrochloric acid was determined for comparison at the same temperature, $t=85^{\circ}$, and with the same amount of sugar. It was found

$$
K=0.0051 \text {. }
$$

FERROUS BROMIDE.

Solutions of this salt were made by adding the proper amount 
of bromine to an excess of iron and water. A reaction soon begins which is hastened by heat. Finally the solution is thoroughly boiled, which eliminates all free bromine and leaves the iron in the ferrous condition. It is then filtered into the cold sugar solution and is ready for use. A solution so made is practically neutral.

\section{EXPERIMENT 22.}

$\mathrm{FeBr}_{2} \cdot 0.54 N$.

In $25^{\circ} \mathrm{cc}$., fifty grams of sugar +14.58 grams of bromide.

$$
A=3 \text { I.43. }
$$

$\begin{array}{rcccc}t . & \alpha . & x . & \log . \frac{A}{A-x} \cdot & \frac{\mathrm{I}}{t} \log \cdot \frac{A}{A-x} . \\ 0 & 23.13^{\circ} & \ldots . & \ldots . & \ldots . . \\ 15 & 16.76 & 6.37^{\circ} & 0.09836 & 0.00655 \\ 45 & 9.76 & 13.37 & 0.24062 & 0.00534 \\ 75 & 6.07 & 17.06 & 0.33988 & 0.00453 \\ 105 & 4.00 & 19.13 & 0.40743 & 0.00388 \\ 165 & 0.68 & 22.45 & 0.54406 & 0.00329 \\ 285 & -4.03 & 27.16 & 0.86691 & 0.00304 \\ 345 & -5.60 & 28.73 & 1.06598 & 0.00309\end{array}$

EXPERIMENT 23.

$\mathrm{FeBr}_{2} \cdot$ I.04 $N$.

In $25^{\circ} \mathrm{cc}$., fifty grams of sugar +28.08 grams of bromide.

$$
A=29.50 \text {. }
$$

$\begin{array}{rcccc}t . & \alpha . & x . & \log \cdot \frac{A}{A-x^{\circ}} & \frac{1}{t} \log \cdot \frac{A}{A-x} . \\ 0 & 21.20^{\circ} & \ldots \ldots & \ldots . . & \ldots . \\ 15 & 13.60 & 7.60^{\circ} & 0.12938 & 0.00862 \\ 45 & 6.22 & 14.98 & 0.30785 & 0.00684 \\ 75 & 2.90 & 18.30 & 0.42060 & 0.00561 \\ 105 & 0.75 & 20.45 & 0.51317 & 0.00489 \\ 165 & -2.70 & 23.90 & 0.72163 & 0.00437 \\ 285 & -6.35 & 27.55 & 1.17979 & 0.00414 \\ 345 & -7.50 & 28.70 & 1.56673 & 0.00454\end{array}$

The normal solutions here invert but little faster than the half-normal. The rates in both cases diminish rapidly from the start, but after the middle of the inversion become nearly constant, as was observed with the ferrous chloride. The first three of the solutions taken from the thermostat had to be filtered before polarizing. 
FERROUS IODIDE.

A half-normal solution was made by mixing 15.87 grams of iodine with an excess of iron and water, in the usual manner. On complete disappearance of the iodine the solution was boiled and filtered into a cold sugar solution. Water was finally added to make the volume up to $250 \mathrm{cc}$. The amount of sugar present is not sufficient to prevent some decomposition on heating, but, as in the other cases referred to, the turbidity at first noticed disappeared after longer warming in the thermostat. The first polarizations were made after filtering, and those later were made directly.

\section{EXPERIMFNT 24.}

$\mathrm{FeI}_{2} \cdot \frac{N}{2}$.

In $250 \mathrm{cc}$, fifty grams of sugar +19.37 grams of iodide.

$$
A=32.03 \text {. }
$$

\begin{tabular}{|c|c|c|c|c|}
\hline$t$. & $\alpha$ & $x$. & $\log \cdot \frac{A}{A-x}$ & $-\frac{I}{t} \log \cdot \frac{A}{A-x}$ \\
\hline 0 & $23.73^{\circ}$ & $\cdots$ & $\ldots$ & $\ldots$ \\
\hline I 5 & 17.45 & $6.28^{\circ}$ & 0.09478 & 0.00632 \\
\hline 30 & 13.57 & Io.16 & $0.1657 \mathrm{I}$ & $0.0055^{2}$ \\
\hline 45 & II. 62 & I2.II & 0.20627 & $0.0045^{8}$ \\
\hline 60 & 9.73 & 14.00 & 0.24956 & 0.00416 \\
\hline 90 & $7 \cdot 50$ & 16.23 & 0.30690 & $0.0034 I$ \\
\hline I $5^{\circ}$ & 4.40 & 19.33 & 0.40176 & 0.00268 \\
\hline 270 & 0.90 & 22.83 & 0.54177 & 0.00200 \\
\hline 390 & -2.80 & 26.53 & 0.76520 & 0.00196 \\
\hline
\end{tabular}

In my former paper a preliminary experiment with ferrous iodide was described in which the coefficient appeared to be nearly constant and much smaller than here. The experiments are, however, not comparable, as in the former case the sugar solution was very strong, containing, in $250 \mathrm{cc}$., 125 grams of sugar. In such a solution the degree of dissociation of the iodide would be necessarily very different from that in a weaker solution. In the strong solution no separation of ferrous hydroxide or other compound appears, even on warming. A strong syrup is much more stable than a weak one, and the lower rate of inversion may be thus easily accounted for. 


\section{CADMIUM CHLORIDE.}

One solution of cadmium chloride was tested as to its inverting power. It was made with a salt purified by several crystallizations at a low temperature, free from uncombined acid.

\section{EXPERIMENT 25.}

$\mathrm{CdCl}_{2}, 0.94 N$.

In $250 \mathrm{cc}$, fifty grams of sugar $+42.95^{8}$ grams of chloride. $A=29.7$ I.

$\begin{array}{rcccc}t . & \alpha . & x . & \log \frac{A}{A-x} \cdot & \frac{I}{t} \log \cdot \frac{A}{A-x}, \\ 0 & 21.41^{\circ} & \ldots \ldots & \ldots \ldots . & \ldots \ldots \\ 15 & \mathrm{I} 2.80 & 8.6 \mathrm{I}^{\circ} & 0.14862 & 0.00990 \\ 30 & 6.59 & 14.82 & 0.3000 \mathrm{I} & 0.01001 \\ 60 & -1.33 & 22.74 & 0.62967 & 0.01049 \\ 90 & -4.89 & 26.30 & 0.94015 & 0.01044 \\ 150 & -7.70 & 29.1 \mathrm{I} & 1.69475 & 0.01129\end{array}$

The rate of inversion is about as rapid as with $0.002 \mathrm{~N}$ hydrochloric acid at the same temperature and same sugar concentration.

\section{IEAD NITRATE.}

A single test was made with a solution containing lead nitrate. The salt was recrystallized from a pure Schuchardt specimen and was weighed in proper amount directly.

EXPERIMENT 26.

$\mathrm{Pb}\left(\mathrm{NO}_{3}\right)_{2}, \frac{N}{2}$.

In $250 \mathrm{cc}$., fifty grams of sugar +20.65 grams of nitrate.

$$
A=33.7 \text {. }
$$

$\begin{array}{rlccc}t . & \alpha . & x . & \log \cdot \frac{A}{A-x} \cdot & \frac{I}{t} \log \cdot \frac{A}{A-x} . \\ 0 & 25.40^{\circ} & \ldots \ldots & \ldots \ldots . & \ldots \ldots \\ 15 & 22.86 & 2.54^{\circ} & 0.03403 & 0.00227 \\ 45 & 17.38 & 8.02 & 0.11803 & 0.00262 \\ 75 & 12.10 & \mathrm{I} 3.30 & 0.21800 & 0.00284 \\ \mathrm{I} 35 & 2.28 & 23.12 & 0.50314 & 0.00372 \\ 195 & -3.63 & 29.03 & 0,8583 \mathrm{I} & 0.00440 \\ 345 & -7.70 & 33.10 & 1.74948 & 0.00507\end{array}$

The coefficient here is found to increase very rapidly, as was noticed by Walker and Aston in their experiments, ${ }^{1}$ which were

1 Loc. cit. 
carried out with a half normal nitrate solution at $80^{\circ}$, but with a weaker sugar solution. The mean value they give from the results of polarization at three intervals is 0.00159 , but the inversion was not carried nearly to completeness, as in the above case.

The experiments given show in a marked manner the extreme variations in the value and constancy of the inversion coefficient and the data obtained may be roughly tabulated as follows:

\begin{tabular}{|c|c|c|}
\hline Potassium alum & \multicolumn{2}{|c|}{$K$ constant. } \\
\hline Ferrous sulphate & \multicolumn{2}{|c|}{ "increases slowly. } \\
\hline Ammonium ferrous sulphate & $"$ " & is \\
\hline Zinc sulphate & $\because$ & " \\
\hline Cadmium chloride & "، & " \\
\hline Manganous sulphate & " & rapidly. \\
\hline Manganous chloride & " & " \\
\hline Lead nitrate & $\because \quad$ " & " \\
\hline Ferrous chloride & \multicolumn{2}{|c|}{ "decreases rapidly. } \\
\hline Ferrous bromide & 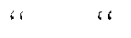 & " \\
\hline Ferrous iodide & “ & ، \\
\hline
\end{tabular}

In the cases of the last three salts the values of $K$ decrease very rapidly at the beginning of the heating, but become nearly constant later, finally, in fact, appearing to increase a little. This behavior seems to bear some relation to the stability of the salts in aqueous or weak saccharine solution. As was mentioned these ferrous halogen solutions became turbid in the thermostat, and the first three or four portions withdrawn in each case for polarization had to be filtered. Later, the liquids became perfectly clear under the influence of longer heating.

During the turbid stage of the reaction, owing to the temporary separation of a trace of base in insoluble form, the amount of free acid present would be relatively increased, and would therefore greatly accelerate the speed of inversion. With the clearing of the solutions on longer heating the normal hydrolysis only would obtain and then the reaction should approach in regularity that due to the presence of a small constant amount of mineral acid.

It was mentioned that the solutions with ferrous sulphate and ferrous ammonium sulphate became likewise turbid on heating. But here the very slight opalescence persisted through the 
whole time of heating, and was perhaps greater at the end of the reaction than at the beginning. Other experiments also show in this respect a marked difference between ferrous sulphate and chloride. In my former paper I referred to solutions of these salts which had been used qualitatively. Portions of these solutions that had not been heated are still in existence. After standing eight months in the light I find that the chloride is practically clear, while the sulphate has become much changed. The bottle contains a decided flocculent precipitate. My former experiments with a strong solution seemed to indicate that at a temperature of $100^{\circ}$ the first slight precipitate which forms disappears, but this is not true of the weaker solutions at $85^{\circ}$..

The slight precipitate of ferrous chloride and other halogen compounds being temporary, while that of ferrous sulphate is apparently permanent, we should expect just such irregularities in the speed of inversion, as the experiments actually show. A solution of manganous sulphate with sugar becomes also slightly decomposed on heating, and the decomposition increases with the time and temperature. At a temperature of $100^{\circ}$ a solution of fifty grams of sugar and ten grams of the sulphate in roo cc. becomes so dark that an exact polarization is not possible, even after filtering. The solution in the present case is much less concentrated, but the precipitate is still marked and its formation is undoubtedly attended by the separation of a little free acid. We should therefore expect an acceleration in the rate of inversion as before.

These considerations do not aid us in explaining, however, the increase in $K$ for manganous chloride, cadmium chloride or lead nitrate. The solutions with these salts are clear and remain so throughout the reaction. In the case of manganous chloride it must be remembered that an almost complete loss of color follows after heating. The pink fades, and in a few hours at the temperature of the thermostat becomes imperceptible in a small volume of the liquid. The color is not restored by cooling. We have here evidently a reaction in which a change takes place in the form of combination of the manganese, with a necessary alteration in the degree of dissociation of the salt. 
It is true, as already said, that most of the bases under consideration form compounds with the sugars, so that we should expect from this cause a slight disturbance at least in the apparent rate of inversion. Too little is known of the optical properties of these saccharose, dextrose and levulose metallic compounds to say just what effect they would have on the rotation, but that they have some action is suggested by the results of some of the polarizations to determine the end point in the inversion. This was usually found a little below the theoretical, $-8.6^{\circ}$ for a 200 $\mathrm{mm}$. tube, but in several cases it was found above after prolonged heating. This was also true of a solution of sugar with manganous chloride, which stood exposed to the light several months.

It must be remembered also that solutions of dextrose are easily oxidized, and those of levulose much more so. The dark color often seen near the end of the reaction, points to such a decomposition.

It will be recognized that a determination of the hydrolysis of many of the heavy metallic salts cannot be measured with great accuracy, because of these several disturbing influences, but a comparison of some little value in the above cases may be made by considering the results obtained at the beginning of the reactions in which the coefficient is an increasing one, and near the end of the reaction in cases where it decreased and then became nearly constant. By taking the mean of the first two values in the one case, and of the last two in the other, we obtain the second column of the table below as the most probable values of the coefficient for half-normal solutions.

In the third column is given a calculation of the extent of hydrolysis of the salts, expressed in per cents. of total salt pres. ent, and based on a comparison with hydrochloric acid acting in 0.00 I normal solution at the same temperature on same amount of sugar. This comparison is at best a rough one, assuming as it does complete hydrolysis of the acid, and neglecting the effect of the excess of undecomposed salts on the rate of inversion. 


\begin{tabular}{|c|c|c|}
\hline & $K$ & $\begin{array}{l}\text { Salt hydrolyzed in } \\
\text { per cent. }\end{array}$ \\
\hline 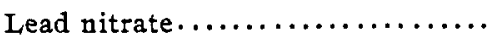 & 0.00244 & 0.096 \\
\hline Manganous chloride $\ldots \ldots \ldots \ldots$ & 0.00095 & 0.035 \\
\hline 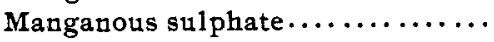 & 0.00052 & 0.020 \\
\hline Ferrous sulphate..$\ldots \ldots \ldots \ldots \ldots$ & 0.00085 & 0.033 \\
\hline Ferrous ammonium sulphate ..... & 0.00068 & 0.026 \\
\hline Zinc sulphate $\ldots \ldots \ldots \ldots \ldots \ldots \ldots$ & 0.00040 & 0.016 \\
\hline 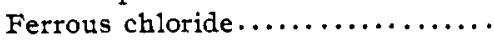 & 0.00164 & 0.063 \\
\hline Ferrous bromide $(0.54 N) \ldots \ldots \ldots$ & 0.00300 & 0.109 \\
\hline Ferrous iodide................ & 0.00198 & 0.078 \\
\hline Potassium aluminum sulphate, $\frac{N}{4}$ & 0.01835 & $\mathrm{I} .440$ \\
\hline Cadmium chloride $0.94 N \ldots \ldots \ldots$. & 0.01000 & 2.080 \\
\hline
\end{tabular}

The amount of hydrolysis is small in all cases except those of the alum and cadmium chloride.

My thanks are due to Mr. S. R. Macy for much assistance in the experimental work of the above.

NoRTHWESTERN UNIVERSITY,

CHICAGO.

\title{
DETERMINATION OF IRON OXIDE AND ALUMINA IN PHOSPHATE ROCK BY THE AMMONIUM ACETATE METHOD.
}

\author{
By Thomas S. GladdiNg. \\ Received June 30,2896 .
}

$7 \mathrm{HE}$ oldest method of separating alumina and iron phosphates from lime phosphate is, probably, the ammonium acetate method. This has been severely criticised, and just at present seems to be under condemnation. The following investigation has convinced the writer that, when properly carried out, not only does the method give an accurate separation of iron and alumina from lime phosphate, but also gives a neutral phosphate of uniform composition from which the iron oxide and alumina present may be accurately estimated.

In brief, the method used is this. If a weakly acid solution of phosphates of iron and alumina together with a large amount of calcium phosphate be slowly poured into a strong solution of ammonium acetate made acid with acetic acid, the iron and alumina are precipitated as phosphates, upon digestion for a short time at a gentle heat. This precipitate, however, con- 